ARTIGOS

\section{CLIMA ORGANIZACIONAL E ADMINISTRAÇÃO PÚBLICA MUNICIPAL: UMA INVESTIGAÇÃO NA CIDADE DE BELÉM DO PARÁ, BRASIL}

\section{RESUMO}

Estudos mostram que as pesquisas de clima organizacional têm avançado na administração pública, contudo ainda estão distantes de produzir resultados semelhantes aos alcançados na iniciativa privada. Para contribuir com essas investigações, este estudo teve como objetivo analisar o clima organizacional em uma autarquia do município de Belém do Pará. A pesquisa, de caráter exploratório e descritivo, foi realizada em pesquisa de campo, com amostragem probabilística aleatória simples, com a participação de 132 servidores. O tratamento de dados foi quantitativo e utilizou estatística descritiva e inferencial (Teste T). Os resultados revelaram que a cooperação e a satisfação com o trabalho foram as dimensões que mais contribuíram para a qualidade do ambiente laboral. Entretanto, a avaliação geral não possibilitou afirmar que os servidores percebem um clima organizacional favorável na autarquia, resultado confirmado pelo teste de hipótese.

Palavras-chave: Comportamento Organizacional. Gestão de Pessoas. Ambiente Organizacional.

\section{INTRODUÇÃO}

As pesquisas de clima organizacional são ferramentas poderosas, despertando o interesse da academia e da gestão organizacional desde a década de 1960. O interesse pelo tema pode ser consequência de sua singular capacidade para realizar diagnósticos acurados e sob medida, em ambientes caracterizados por complexas inter-relações pessoais, que envolvem tanto os trabalhadores entre si, quanto os trabalhadores e a organização. Assim, as investigações de clima organizacional possibilitam, antes de tudo, evidenciar os aspectos que precisam da atenção da gestão, para assegurar um ambiente de trabalho saudável e produtivo (SALGADO; AIRES; ARAÚJO, 2013). Pereira e Vidal (2011) destacam que pessoas desmotivadas em ambientes desfavoráveis prejudicam o rendimento do trabalho e ensejam maior quantidade de erros e retrabalhos. Por outro lado, é verdade também, segundo os autores, que pessoas motivadas, que alinham seus objetivos com as metas da organização, potencializam resultados benéficos para ambos. 
Desde que Forehand e Gilmer (1964), Pelz e Andrews (1966) e Litwin e Stringer (1968) propuseram o conceito de clima organizacional e a necessidade de aprofundar seu conhecimento como um instrumento de gestão capaz de facilitar o acompanhamento das condições do ambiente de trabalho, eles despertaram o interesse de diversos pesquisadores (SANTOS, 1999; MÓL et al., 2010; GONÇALVES, 2012; HOLLOWAY, 2012), nos mais diferentes setores da economia e nos mais distantes locais do planeta.

Caracterizado por um conjunto de aspectos típicos do ambiente de trabalho que, segundo a avaliação dos trabalhadores, podem ser percebidos como satisfatórios, ou não, o clima organizacional contribui para a compreensão de como os estímulos recebidos no local de trabalho influenciam no comportamento de suas equipes. Nessa perspectiva, o clima possibilita acompanhar o estado de ânimo dos integrantes da organização. Essa peculiaridade confere às pesquisas de clima uma capacidade privilegiada para auxiliar na formulação e seleção de estratégias organizacionais, especialmente as relacionadas com a gestão de pessoas (LUZ, 2012; PEREIRA; VIDAL, 2011).

Tamayo (2004, p. 88) destaca que: “[...] o clima organizacional refere-se à forma como o ambiente organizacional é percebido e interpretado pelos empregados", por sua vez, ao ser expresso nas pesquisas de clima organizacional, ele materializa a percepção compartilhada dos trabalhadores, transcendendo aquela unicamente individual. Provavelmente, o maior poder das pesquisas de clima advenha de sua capacidade de sintetizar um conjunto de aspectos complexos e variados do ambiente de trabalho em um instrumento sob medida para a organização, abrangendo diversos departamentos e fornecendo informações que vão além das preocupações dos profissionais de recursos humanos ao fornecer subsídios para gestores nos três níveis de gerência - baixa, média e alta.

Diversas pesquisas (MATOS, 2007; SALVADOR; MACHADO; ALMEIDA, 2013) reforçam que o clima organizacional está rela- cionado à moral e à satisfação das necessidades dos trabalhadores e pode-se apresentar quente ou frio, negativo ou positivo, falho ou satisfatório. Portanto, a analogia com as condições do clima atmosférico expressa bem o significado do construto, que expressa, essencialmente, a forma de sentir dos trabalhadores quanto à organização. As pesquisas de clima no Brasil avançaram muito na área da administração privada. No serviço público, até recentemente, ainda eram um fenômeno pouco estudado (MÓL et al., 2010).

Dessa forma, o presente artigo tem como objetivo analisar o clima organizacional em uma autarquia do município de Belém do Pará, Brasil, e, assim, diagnosticar a qualidade do ambiente de trabalho. Considerando esse objetivo, a investigação se concentrou em responder ao questionamento: qual é a percepção dos servidores quanto à qualidade do clima organizacional em uma autarquia do município de Belém do Pará, Brasil? Para responder a essa pergunta, foi feita uma pesquisa no próprio local de trabalho dos servidores públicos e estabeleceu-se como hipótese a ausência de evidência estatística (H0) que possibilite afirmar que os servidores públicos percebam o clima organizacional como satisfatório no local da pesquisa.

\section{CLIMA ORGANIZACIONAL}

O clima organizacional tem como função essencial retratar a presença ou ausência de aspectos afetivos no ambiente organizacional, interpretado segundo as particularidades de cada trabalhador e de cada organização (MARTINS, 2008), caracterizado como um indicador de satisfação com o ambiente laboral; ele é um reflexo de diferentes aspectos da realidade aparente da empresa (CODA, 1997; ABREU et al., 2013).

Estudos contemporâneos (MANTOVANI; GREATTI, 2010; ABREU et al., 2013) constataram que um clima organizacional favorável beneficia tanto a organização, quanto aos trabalhadores; ao passo que, se ele for desfavorável, ambos assumem seu ônus. Por sua vez, o diagnóstico acurado do clima organizacional tornou- 
-se uma ferramenta essencial para a gestão de organizações modernas tanto privadas, quanto públicas, nas quais, se por um lado as organizações privadas enfrentam progressivamente maior quantidade e mais eficientes concorrentes, as organizações públicas devem atender aos anseios de uma sociedade cada vez mais exigente e organizada. Nessa perspectiva, Araújo e Garcia (2009, p. 5) complementam ao afirmar:

O gestor de pessoas deve ser hábil no sentido de identificar eventuais ruídos no relacionamento entre as pessoas, visando ao melhor clima possível, assegurando um desenvolvimento regular dos trabalhos na organização. $\mathrm{O}$ melhor clima possível não elimina a existência de conflitos, mas deve eliminar o conflito predador, aquele que só traz instabilidade e incerteza.

Estudos empíricos (MANTOVANI; GREATTI, 2010; SALGADO; AIRES; ARAUJO, 2013) mostram a influência do clima organizacional no desempenho profissional dos trabalhadores. A natureza do clima pode ser compartilhada, individual, grupal ou organizacional, uma vez que o clima de uma organização pode variar entre seções, departamentos, filiais etc., além de receber outras influências diversas, como aquelas que têm origem na cultura, nas crenças, expectativas e na personalidade. Desta forma, o clima exprime as características da organização projetada nos trabalhadores, materializando-se em suas ações cotidianas.

O clima organizacional pode ser mensurado pelas pesquisas e, com isso, identifica as condições e os relacionamentos estabelecidos entre os trabalhadores e a organização. Quando se faz uma pesquisa de clima, obtêm-se respostas mais precisas a respeito da opinião dos trabalhadores. As pesquisas de clima organizacional podem utilizar metodologias qualitativas, quantitativas ou mistas, e a opção por uma dessas metodologias se prende aos objetivos dos pesquisadores. Ao empregar corretamente as pesquisas de clima, são obtidas informações valiosas que, se utilizadas corretamente, podem contribuir para o aumento da produtividade, qualidade de trabalho, reduzir abstenções, adoecimentos, turnover, entre outros (PEREIRA; VIDAL, 2011).

Lim e Eo (2014), ao realizarem estudos em uma escola de ensino fundamental na Coreia do Norte, constataram que a eficiência dos professores ao passar conhecimentos para seus alunos é diretamente influenciada pelo clima organizacional. Por outro lado, a falta de diálogo com os trabalhadores sobre as necessidades para a realização das tarefas promoveu um distanciamento da política organizacional, além de deteriorar o desempenho de professores e alunos. Assim, os resultados da investigação possibilitaram simplificar o processo de comunicação e aumentar a integração das equipes de trabalho.

Em complemento, Pereira e Nasser (2013), com base nos resultados obtidos em uma pesquisa de clima organizacional, realizada em um hemocentro, desenvolveram um plano de melhorias com revisões periódicas. Ao adotar essas revisões, com intervalos anuais, foi possível observar a evolução no desempenho de cada dimensão pesquisada e, com isso, foram dirigidas ações de enfrentamento a problemas específicos, promovendo, com essa estratégia, ciclos de melhorias contínuas no ambiente de trabalho.

As investigações de clima organizacional são feitas considerando um conjunto de dimensões. Não há uniformidade na literatura quanto às dimensões que devem estar presentes nas pesquisas de clima organizacional. Se, por um lado, isso possibilita desenvolver soluções sob medida, por outro, enseja críticas como aquelas feitas por Kubo et al. (2015) ao se referirem à falta de consensualidade nas conceituações de clima e nas suas dimensões propriamente ditas. As dimensões dizem respeito a assertivas reunidas por temática e utilizadas para sistematizar a investigação, conferindo-lhe racionalidade, elas podem ser compreendidas também como variáveis semelhantes reunidas com base em aspectos específicos do ambiente de trabalho. A quantidade de variáveis e dimensões é tão diversificada que elas ensejaram diferentes mo- 
delos de avaliação de clima que se estendem desde aspectos da estrutura física organizacional a riscos, recompensas, conflitos, participação na tomada de decisões, comunicação na organização, trabalho em equipe, chefias, assim como aspirações, valores, aptidões e diferenças sociais, entre outros (ARABACI, 2010; PEREIRA; VIDAL, 2011), cada pesquisa adota um conjunto de aspectos próprios considerados como mais adequados para a organização.

Abreu et al. (2013) mostram que as pesquisas de clima trazem uma contribuição efetiva para a comunicação organizacional por possibilitar que os trabalhadores expressem sua opinião quanto ao seu ambiente de trabalho. As pesquisas normalmente adotam classificação desfavorável, neutra ou favorável para designar as condições organizacionais. Essa é a forma mais frequente e a comum entre os autores (SPIRI, 1998; MELLO, 2004; MOTTA, 2006; HEINZMANN; SILVA, 2014). O clima desfavorável revela um ambiente conflituoso, com reclamações, rejeições e negatividade. Já o clima neutro, de monotonia apática, mostra desinteresse e falta de criatividade. O clima favorável se caracteriza pela receptividade, satisfação, proatividade e harmonia. Nessa perspectiva, observa-se que é possível aumentar a eficiência da organização pela construção de um clima organizacional que alcance as necessidades dos indivíduos e canalize seu comportamento, direcionando-o à busca dos objetivos organizacionais (HEINZMANN; SILVA, 2014).

Heinzmann e Silva (2014) reforçam a compreensão de que o clima e a cultura organizacional são fortemente relacionados. Luz (2012, p. 12) esclarece e conceitua clima organizacional como "o reflexo do estado de ânimo ou do grau de satisfação dos funcionários de uma empresa, num dado momento." Por sua vez, a cultura organizacional, como destacado por Robbins (2014), representa o conjunto de valores compartilhados pelos membros da organização, de tal maneira que seus integrantes os percebem como características essenciais da organização e, com base neles, pautam seus comportamentos e condutas organizacionais, mesmo que inconscientemente. Dessa forma, a cultura se reflete no clima organizacional, evidenciando fenômenos complementares, nos quais o clima se manifesta na perspectiva temporal, enquanto a cultura transcende essa compreensão, assumindo um caráter mais profundo, estável e atemporal.

\section{GESTÃO DE PESSOAS NA ADMI- NISTRAÇÃO PÚBLICA}

O trabalho, ao longo dos anos, revelou-se mais do que uma atividade para obter recursos e manter a sobrevivência pessoal e familiar, uma vez que ele representa uma oportunidade de integração à sociedade e de alcançar realização pessoal. É pelo trabalho que o indivíduo desenvolve suas capacidades, aumenta sua autoestima, torna-se produtivo e obtém boa parte da sua satisfação pessoal com a vida. Essa compreensão posiciona a atividade laboral como uma forma privilegiada de realização pessoal e, quando o trabalho executado vai ao encontro do bem comum e dos interesses públicos, ele se torna ainda mais gratificante (VIEIRA et al., 2011) como é o caso de muitos servidores públicos.

Perceber a função do trabalho na vida dos servidores públicos e sua necessidade de autodesenvolvimento pessoal é um elemento fundamental para criar as condições necessárias à melhoraria da qualidade dos serviços oferecidos pela administração pública, uma vez que a capacidade de oferecer esses serviços depende, em grande parte, do envolvimento dos trabalhadores (CARAPETO; FONSECA, 2014). Contudo, em muitas organizações, tanto públicas, quanto privadas, ainda prevalece uma compreensão da atuação da gestão de pessoas voltada ao controle de pessoal em detrimento de uma perspectiva mais moderna, que se antecipa ao mercado e obtém melhores resultados por se deslocar de uma posição operacional e reativa para uma postura estratégica e proativa (BERGUE, 2014; MELLO; AMÂNCIO FILHO, 2010).

Quanto à administração pública, os esforços para melhorar os serviços oferecidos à 
sociedade resultaram ao longo dos anos em um amplo conjunto de reformas, que tiveram a finalidade principal de adequar a estrutura estatal às constantes mudanças nas exigências da sociedade, especialmente quanto à agenda e à utilização mais racional dos recursos públicos. Bergue (2014) reforça essa compreensão ao afirmar que a sociedade exige da administração pública resultados efetivos. Assim, a qualidade e a adequação dos serviços públicos são aspectos decisivos para o bom desempenho de qualquer organização pública. Esse processo desencadeou, entre outros de cunho administrativo, a valorização da qualificação dos servidores públicos, que passaram, progressivamente, a exercer atividades mais complexas. No Brasil, o marco inicial de paradigma ocorreu na década de 1930, com a adoção do Modelo Burocrático de administra- ção pública, e foi, em certa medida, formalizado com a criação do Departamento de Administração do Serviço Público (DASP).

Ao longo do tempo, outras reformas se sucederam para refletir os momentos vividos pelo país, até que, na década de 1990, ocorreu a adoção do Modelo Gerencial de Administração Pública no Brasil, também denominado como Nova Administração Pública. O modelo foi organizado pautado entre um amplo conjunto de medidas; entre elas, a adaptação e transferência de práticas da administração privada para a área pública (RIBEIRO; PEREIRA; BENEDICTO, 2013). As diferenças entre os dois modelos, o Burocrático e o Gerencial, no âmbito da organização do trabalho, Quadro 1, foram mostrados por Carapeto e Fonseca (2014).

\begin{tabular}{|l|l|}
\hline \multicolumn{1}{|c|}{ Modelo Burocrático } & \multicolumn{1}{|c|}{ Modelo Gerencial (Pós-Burocrático) } \\
\hline $\begin{array}{l}\text { Estrutura organizacional hierárquica rígida com muitos } \\
\text { níveis }\end{array}$ & $\begin{array}{l}\text { Estrutura organizacional mais horizontal e } \\
\text { flexível com menos chefias intermediárias }\end{array}$ \\
\hline $\begin{array}{l}\text { Cadeia de comando de cima para baixo, centralização } \\
\text { do processo decisório }\end{array}$ & $\begin{array}{l}\text { Participação dos trabalhadores no processo } \\
\text { decisório (empowerment) e partilha de } \\
\text { informações }\end{array}$ \\
\hline $\begin{array}{l}\text { Divisão de trabalho especializado e limitação no } \\
\text { âmbito das tarefas }\end{array}$ & $\begin{array}{l}\text { Ampliação do trabalho em equipe e no âmbito } \\
\text { das tarefas }\end{array}$ \\
\hline $\begin{array}{l}\text { Tarefas administrativas e repetitivas realizadas pela } \\
\text { maioria dos trabalhadores do setor público }\end{array}$ & $\begin{array}{l}\text { Trabalho especializado com maior necessidade } \\
\text { de conhecimentos e habilidades }\end{array}$ \\
\hline Trabalho regido por regras e regulamentos rígidos & $\begin{array}{l}\text { Trabalho regido por delegação de } \\
\text { responsabilidades }\end{array}$ \\
\hline Formação do trabalhador & Aperfeiçoamento contínuo \\
\hline Mobilidade de carreira vertical limitada a uma minoria & $\begin{array}{l}\text { Progressão tanto horizontal, quanto vertical na } \\
\text { carreira }\end{array}$ \\
\hline Fraca importância dada ao ambiente de trabalho & $\begin{array}{l}\text { Valorização de um ambiente de trabalho } \\
\text { saudável e positivo. }\end{array}$ \\
\hline
\end{tabular}

Quadro 1 - Organização do trabalho no setor público, práticas em declínio e fortalecimento

Fonte: adaptado pelos autores deste trabalho com base em Carapeto e Fonseca (2014, p. 210).

Combs et al. (2006) reforçam a compreensão de que aprimorar as práticas de gestão de pessoas em uma perspectiva contemporânea de valorização humana influencia positivamente o desempenho organizacional em uma concepção ampla, que se estende, desde os produtos e serviços em si, até aspectos financeiros, de produ- tividade, entre outros, pois a gestão de pessoas motiva os servidores e exerce forte influência para que eles utilizem suas habilidades particulares em benefício da organização, tendo sido encontradas constatações semelhantes em outros estudos, como o de Moro et al. (2012).

Notoriamente, as particularidades da 
administração pública são muito diferentes daquelas do setor privado, especialmente quanto a suas finalidades e práticas, incluindo formas de recrutamento, seleção e contratação, políticas de remuneração, métodos de avaliação de desempenho, entre outras. Essas particularidades devem ser consideradas quando se tratar de recursos humanos e gestão de pessoas, ensejando atenção para adaptação e sua transposição do setor privado para o público (FERREIRA et al., 2007; MATTOS et al., 2015).

A gestão de pessoas na administração pública brasileira obteve avanços expressivos ao longo do tempo, sendo as pesquisas de clima organizacional uma das dimensões desse processo que podem ser percebidas pela maior delegação de poder nas organizações públicas, descentralizações de processos (KETTL, 2005), ampliação da meritocracia (FARIAS; GAETANI, 2002), adoção de estruturas organizacionais mais flexíveis, desenvolvimento de competências, aprimoramento do trabalho em equipe (SILVA; MELLO, 2013), entre outros aspectos. Logicamente, muitas das conquistas ainda precisam ser ampliadas e sedimentadas, outras ainda representam desafios a serem superados pela administração pública, especialmente quando se trata do aumento da produtividade, barreiras culturais, entre outras (BERGUE, 2014).

\section{MÉTODO}

A análise do clima organizacional na autarquia utilizou uma metodologia, que, segundo Sampieri, Collado e Lúcio (2013), classifica-se como exploratória e descritiva, operacionalizada na forma de survey, com amostragem probabilística aleatória simples e tratamento quantitativo de dados. A amostra foi calculada com base no total de servidores lotados no órgão, que, por ocasião da fase exploratória, contava com 304 trabalhadores. A amostra foi calculada com $90 \%$ de margem de segurança e 5\% de erro, o que resultou em 144 questionários, conforme a Fórmula (1) apresentada em Pinheiro et al. (2009):

$$
n=\frac{S * Z^{2} * N}{\left(S * Z^{2} * e^{2}(N-1)\right)}
$$

Em que: $\mathrm{n}=$ tamanho da amostra; $\mathrm{S}=$ variância da amostra; $Z^{2}=$ desvio padrão ao quadrado; relacionado ao índice de confiança; $\mathrm{e}^{2}=$ erro amostral ao quadrado; e $\mathrm{N}=$ tamanho do universo.

No tratamento dos dados, 12 questionários foram descartados por apresentarem erros de preenchimento e presença de valores perdidos, o que elevou levemente o erro amostral para 5,38\%. Assim, ao final do levantamento, foram obtidos 132 questionários de pesquisa válidos. O questionário utilizado na investigação foi estruturado em duas seções. A primeira, com sete questões de múltipla escolha, teve a finalidade de caracterizar o perfil socioeconômico dos entrevistados. A segunda, com 42 questões distribuídas em nove dimensões (Quadro 2), foram elaboradas com respostas na escala intervalar de Likert, com sete opções na escala, sendo um para discordo totalmente; dois para discordo muito; três para discordo pouco; quatro para não sei, ou não discordo nem concordo; cinco para concordo pouco; seis para concordo muito; e sete para concordo totalmente. 


\begin{tabular}{|l|l|}
\hline \multicolumn{1}{|c|}{ Dimensão } & \multicolumn{1}{c|}{ Autores } \\
\hline Comunicação organizacional & Coda (1997) e Silva (2003) \\
\hline Imagem organizacional & Rizzatti (1995), Silva (2003) e Luz (2012) \\
\hline Cooperação na organização & $\begin{array}{l}\text { Rizzatti (1995), Coda (1997), Luz (2012), Martins et al. (2008) e Mól } \\
\text { et al. (2010) }\end{array}$ \\
\hline Remuneração e recompensa & $\begin{array}{l}\text { Kolb et al. (1978), Sbragia (1983), Coda (1997), Silva (2003), Luz } \\
\text { (2012), Martins et al. (2008) e Mól et al. (2010) }\end{array}$ \\
\hline Satisfação no trabalho & Colossi (1991) e Rizzatti (1995) \\
\hline Equidade & La Follete e Sims (1975) e Mól et al. (2010) \\
\hline Participação nas decisões & Sbragia (1983) e Luz (2012) \\
\hline Valorização do servidor & Rizzatti (1995), Coda (1997) e Luz (2012) \\
\hline Modernidade organizacional & Rizzatti (1995), Silva (2003), Luz (2012) e Mól et al. (2010) \\
\hline
\end{tabular}

Quadro 2 - Fundamentação teórica das dimensões investigadas na pesquisa Fonte: elaborado pelos autores.

Para atender aos padrões de ética em pesquisas com seres humanos, os entrevistados assinaram o Termo de Consentimento Livre e Esclarecido (TCLE), tendo suas identidades preservadas, assim como a organização local da pesquisa. A consistência interna do instrumento foi testada, assim como suas dimensões. A forma de medição foi o coeficiente alpha de Cronbach, conforme a Fórmula (2), apresentada em Costa (2011).

$$
\alpha=\frac{\mathrm{k}}{\mathrm{k}-1}\left(1-\frac{\sum_{i=1}^{\mathrm{k}} \sigma_{i}^{2}}{\sigma_{\mathrm{y}}^{2}}\right)
$$

Em que: k é o número de itens do ques- tionário; $\sigma_{\mathrm{i}}^{2}$ é a variância do item $\mathrm{i}$; e $\sigma_{\mathrm{y}}^{2}$ é a variância da escala total somada.

Apesar de não existir um valor que seja consenso quanto ao índice mais adequado para o alpha de Cronbach (KLINE, 1998), índices superiores a 0,600 e 0,700 são aceitos como adequados pela maioria dos autores (KLINE, 1998; HAIR JUNIOR et al., 2009; COSTA, 2011). Dessa forma, a investigação neste estudo resultou em níveis elevados para o coeficiente alpha de Cronbach, Tabela 1, uma vez que todas as dimensões alcançaram índices superiores a 0,798. 
Tabela 1 - Alpha de Cronbach das dimensões e do instrumento de pesquisa

\begin{tabular}{l|l|l}
\hline Dimensão & $\mathrm{N}^{\circ}$ de Variáveis & Alpha de Cronbach \\
\hline Comunicação organizacional & 5 & 0,798 \\
\hline Imagem organizacional & 5 & 0,872 \\
\hline Cooperação na organização & 6 & 0,818 \\
\hline Remuneração e recompensa & 5 & 0,887 \\
\hline Satisfação no trabalho & 4 & 0,835 \\
\hline Equidade & 4 & 0,818 \\
\hline Participação nas decisões & 5 & 0,811 \\
\hline Valorização do servidor & 4 & 0,811 \\
\hline Modernidade organizacional & 4 & 0,870 \\
\hline Questionário & 42 & 0,970
\end{tabular}

Fonte: elaborado pelos autores.

O tratamento de dados foi integrado com estatística inferencial. Para tanto, foi utilizado o Teste T (Fórmula 3) para uma amostra (BRUNI, 2009). Esse teste paramétrico foi selecionado para verificar se a média das respostas dos servidores era significativamente superior ao valor intermediário da escala, ou seja, se a média amostral era superior a 4,00. Caso afirmativo, o resultado do teste sugeriria concordância com as variáveis e indicaria um clima organizacional favorável. Por outro lado, médias inferiores a 4,00 revelariam discordância quanto às variáveis e, assim, clima organizacional desfavorável.

$$
t=\frac{\bar{x}-\mu_{0}}{\frac{s}{\sqrt{n}}}
$$

Em que: é a média da amostra; a média da população (referência); s é o desvio padrão; e n é o número de observações.

Assim, no contexto da investigação, a utilização do teste $\mathrm{T}$ teve como finalidade testar as hipóteses e verificar se a população se comportava conforme a hipótese nula (H0). Para tal, foi estabelecido o nível de significância de $5 \%(\alpha=0,05)$ para a região crítica de aceitação ou recusa de $\mathrm{H} 0$. Isso posto, as hipóteses foram estabelecidas conforme abaixo:

H0: $\mu \leq 4,00$, não se pode afirmar que os entrevistados percebam um clima organizacional favorável na organização.
H1: $\mu>4,00$, existem evidências estatísticas para afirmar que os entrevistados consideram o clima organizacional favorável na organização.

Como recomenda Malhotra (2011), os testes paramétricos devem ser utilizados quando as variáveis estejam, pelo menos, em escala intervalar. $\mathrm{O}$ autor reforça que o teste $\mathrm{T}$ é o mais utilizado quando se pretende testar suposições baseadas na média e que ele exige uma amostra com distribuição aproximadamente normal para ser utilizado. Neste estudo, o teste assumiu uma condição unilateral à direita. Assim, se a significância do teste for menor ou igual a $5 \%\left(\frac{\text { sig. }}{2} \leq \alpha\right)$ e o sinal da estatística de teste positivo $(\mathrm{t}>0)$, rejeita-se a $\mathrm{H} 0$ e constata-se um clima organizacional positivo na autarquia investigada.

\section{APRESENTAÇÃO E DISCUSSÃO DE RESULTADOS}

A maioria dos servidores que participaram da pesquisa foi do sexo masculino, 69,7\% (92). Quanto à idade, os servidores tinham, em média, 38 anos $( \pm 11)$ por ocasião da entrevista. Os entrevistados evidenciaram escolaridade elevada, uma vez que $46 \%$ (61) tinham curso superior. A situação funcional de ocupantes de cargos efetivos, em 98,5\% (130) dos casos, foi de profissionais concursados. Os servidores declararam 
renda entre $1.485,00$ e 4.861,00 reais por mês em 63\% (83) das repostas. Quanto à distribuição da amostra entre departamentos e cargos, a pesquisa envolveu 33 departamentos e 29 cargos, que representaram praticamente a totalidade da estrutura organizacional da autarquia.

$\mathrm{Na}$ avaliação do clima organizacional (Tabela 2), o melhor aspecto do ambiente organizacional foi a dimensão Cooperação $(4,75 \pm 1,72)$. Diversos estudos (ARABACI, 2010; SALGADO NETO, 2001; SHIM, 2010) destacam a cooperação como um elemento necessário para a promoção de um clima organizacional favorável, integrado e produtivo. A cooperação diminui as barreiras interdepartamentais e favorece fortemente a possibilidade de trabalhos em equipe. Desta forma, ao avaliarem a Cooperação Organizacional, os servidores revelaram uma dimensão positiva do ambiente de trabalho, uma vez que, além de a média ser a maior da pesquisa na escala entre 1 e 7 , a mediana $(5,00)$ e a moda $(5.00)$ posicionaram-se na parte superior da escala, reforçando uma compreensão positiva da dimensão.
(ROBBINS, 2014). Outros aspectos positivos foram a disposição para trabalhos em equipe (78\%), a integração entre os departamentos, que trabalham de forma cooperada (77\%), a habilidade para resolver os desentendimentos (71\%) e a contribuição das chefias na execução das tarefas (69\%). Esse conjunto mostra um ponto forte que deve ser aproveitado pela organização, uma vez que facilita ações conjuntas e contribui fortemente para criar sinergia organizacional.

A dimensão Satisfação no Trabalho, segunda melhor avaliação da pesquisa $(4,40 \pm 2,00)$, revelou outra dimensão positiva do ambiente organizacional. Destacaram-se na investigação a satisfação com que são feitas as tarefas (81\%) e a motivação envolvida em sua realização $(73 \%)$. Nesse contexto, a maioria dos entrevistados manifestou realização profissional por trabalhar no órgão (59\%), mas preocupa o fato de eles não perceberem possibilidade de ascensão profissional na autarquia (59\%), mostrando, assim, um aspecto negativo da organização. Essa circunstância se revela

Tabela 2 - Análise descritiva das dimensões do clima organizacional no local da pesquisa

\begin{tabular}{l|c|c|c|c|c|c|c}
\hline Dimensão & Média & Mediana & Moda & Máximo & Mínimo & $\begin{array}{c}\text { Desvio } \\
\text { Padrão }\end{array}$ & CV (\%) \\
\hline Cooperação na organização & 4,75 & 5,00 & 5,00 & 7,00 & 1,00 & 1,72 & 36,21 \\
\hline Satisfação no trabalho & 4,40 & 5,00 & 6,00 & 7,00 & 1,00 & 2,00 & 45,45 \\
\hline Comunicação organizacional & 4,38 & 5,00 & 5,00 & 7,00 & 1,00 & 1,91 & 43,60 \\
\hline Equidade & 4,00 & 4,00 & 4,00 & 7,00 & 1,00 & 1,96 & 49,00 \\
\hline Participação nas decisões & 3,73 & 4,00 & 1,00 & 7,00 & 1,00 & 1,97 & 52,81 \\
\hline Imagem organizacional & 3,64 & 4,00 & 4,00 & 7,00 & 1,00 & 1,86 & 51,09 \\
\hline Remuneração e recompensa & 3,56 & 4,00 & 4,00 & 7,00 & 1,00 & 1,83 & 51,40 \\
\hline Modernidade organizacional & 3,44 & 3,00 & 2,00 & 7,00 & 1,00 & 1,83 & 52,81 \\
\hline Valorização do servidor & 3,39 & 3,00 & 1,00 & 7,00 & 1,00 & 1,93 & 56,93 \\
\hline
\end{tabular}

Legenda: $\mathrm{CV}=$ Coeficiente de variação.

Fonte: dados da pesquisa.

A Cooperação Organizacional mostrou o apoio aos novatos durante o aprendizado das tarefas (81\%), condição que facilita o processo de socialização e, assim, contribui para aumentar o comprometimento e a produtividade, reduzir a rotatividade e o hiato entre as expectativas do recém-chegado e a realidade organizacional especialmente perigosa, uma vez que, como destacam Schneider (1978) e Siqueira (2008), a satisfação com o trabalho se fundamenta em um conjunto de aspectos; entre eles, a possibilidade de ascensão na forma de carreira. Assim, apesar de a satisfação com o trabalho representar uma dimensão favorável ao ambiente 
organizacional; no futuro, a impossibilidade de promoções revela-se como uma ameaça que merece a atenção da alta administração, pois pode contribuir para apatia, acomodação e desânimo para os servidores.

Quanto à avaliação da Comunicação Organizacional, com média $(4,38 \pm 1,96)$, moda e mediana $(5,00)$, todas acima do ponto intermediário da escala, observou-se outro aspecto favorável do ambiente de trabalho. A avaliação da comunicação mostrou que os entrevistados atribuíram a terceira melhor média da pesquisa entre as dimensões investigadas. Destacaram-se entre os aspectos positivos: (1) a confiança nas informações recebidas dos superiores hierárquicos $(75 \%)$ e (2) a clareza no processo comunicacional (83\%). Observa-se que, a maioria dos superiores hierárquicos discutem com suas equipes os resultados das ações organizacionais (55\%); além disso, eles conhecem os objetivos da organização (52\%). Contudo, os servidores não recebem feedback, quanto a seu desempenho $(53 \%)$. Isso pode estar relacionado com a falta de hábito de utilizar a avaliação de desempenho como um instrumento de melhoria contínua, uma vez que essa prática ainda é pouco realizada na administração pública, como destaca Luz (2012), ou ainda pode ser o resultado de deficiências na gestão que dificultam a avaliação individual dos servidores.

A análise da dimensão Equidade dividiu a avaliação do clima organizacional, uma vez que, até essa dimensão, predominaram os aspectos positivos do ambiente de trabalho e, a partir dela, posicionaram-se as avaliações de caráter prejudicial ao clima organizacional. Nessa perspectiva, a Equidade, de maneira geral, apresentou avaliação intermediária, com média, mediana e moda, com valores no meio da escala $(4,00)$ e desvio padrão intermediário $(1,96)$. Como características positivas, destacam-se o respeito aos servidores, aspecto que obteve a concordância de 70\% (92) dos entrevistados, além do sentimento de serem avaliados com justiça pelos superiores hierárquicos (70\%). Entretanto, os servidores discordam que as promoções ocorram por merecimento (69\%) da mesma forma que as tarefas sejam distribuídas de forma justa (60\%).

\section{A Participação nas Decisões} $(3,73 \pm 1,97)$, outra dimensão investigada na pesquisa, foi considerada prejudicial ao clima organizacional; a moda com valor unitário reforça essa compreensão (Tabela 2). Os servidores declararam que as chefias recebem bem as sugestões e contribuições $(70 \%)$, e que se sentem livres para expressá-las, tanto quanto à organização, quanto com relação às tarefas (70\%). Contudo, eles não participam das decisões de planejamento, como definição de objetivos, indicadores e metas (69\%), além de não terem liberdade para organizar suas tarefas e avaliá-las da melhor forma (60\%). Limitações na participação entre servidores públicos também foram identificadas por Mól et al. (2010) em pesquisa na administração pública estadual no estado do Rio Grande do Norte. Essa peculiaridade expressa a presença do modelo burocrático de gestão, que ainda se perpetua em diversas organizações públicas.

A análise da dimensão Imagem Organizacional $(3,64 \pm 1,86)$ revelou uma fraqueza da organização na opinião dos servidores, uma vez que eles consideram que a autarquia tem uma imagem negativa perante a sociedade (75\%), da mesma forma que a sociedade não está satisfeita com os serviços prestados pela organização (77\%). Contudo, os servidores consideram seus superiores como bons exemplos para a organização $(60 \%)$ e notam que a autarquia é respeitada por outras organizações municipais $(51 \%)$.

Conforme a Tabela 2, a dimensão Remuneração e Recompensa $(3,56 \pm 1,83)$ revelou outra dimensão prejudicial ao clima. Uma vez que os entrevistados consideram que seus salários são menores do que os da iniciativa privada $(73 \%)$ e, até mesmo, em relação a outros profissionais da administração pública municipal, que realizam tarefas semelhantes. A maioria dos entrevistados considera insuficiente a remuneração para atender às necessidades básicas $(56 \%)$ e há insatisfação com os benefícios oferecidos pela administração municipal 
(62\%). Esses resultados colocam a dimensão entre as que mais prejudicam o clima organizacional. Na avaliação do clima, a remuneração se revela como um elemento central para a promoção de um ambiente de trabalho motivador, que seja capaz de conquistar o engajamento dos servidores com os objetivos organizacionais e que atue para a manutenção do capital humano na organização (HUNTER; PERRY; CURRAL, 2011; MÓL et al., 2010).

As piores avaliações da pesquisa (Tabela 2) ocorreram nas dimensões Modernidade Organizacional $(3,44 \pm 1,83)$ e Valorização dos Servidores $(3,39 \pm 1,93)$. Assim, quanto à Modernidade Organizacional, as condições físicas do local de trabalho são insatisfatórias (51\%), os equipamentos de informática $(65 \%)$ e os sistemas de informação não atendem às necessidades do trabalho (59\%) e a organização resiste negativamente às inovações em práticas de gestão (63\%). As limitações do ambiente físico de trabalho prejudicam a produtividade e o desempenho organizacional, uma vez que, mesmo que os trabalhadores estejam motivados, para que possam alcançar a produtividade esperada pela organização, devem dispor de condições adequadas de trabalho.

Quanto à dimensão Valorização do Servidor, os entrevistados não percebem oportunidades de desenvolvimento profissional (69\%), não recebem treinamento $(66 \%)$, nem acreditam que a política de recursos humanos valorize os servidores (69\%). Contudo, o aprendizado dos servidores é aproveitado na organização, sendo opinião compartilhada pela maioria dos servidores $(60 \%)$. Esses resultados mostram o baixo investimento da administração pública municipal na qualificação dos servidores públicos. $\mathrm{O}$ desenvolvimento de competências e a valorização profissional representam uma preocupação da administração pública, que busca oferecer melhores serviços públicos. Contudo, segundo a opinião dos entrevistados, essa preocupação não ocorre no local da pesquisa.

A avaliação geral do clima organizacional foi feita pelo Teste $\mathrm{T}$ calculado, com base na média amostral das variáveis. Apesar de o tamanho da amostra $(\mathrm{n}>30)$ atender ao Teorema do Limite Central (TLC), a forma da distribuição amostral foi testada com o teste Shapiro-Wilks ( $p$-valor $=0,204)$ para confirmar que ela não era fortemente assimétrica. $\mathrm{O}$ resultado do teste confirmou que a distribuição era aproximadamente normal, portanto, adequada ao teste selecionado.

Conforme a Tabela 3, a média amostral foi de 3,95, abaixo do valor de referência $(4,00)$, e o desvio padrão foi baixo, 1,18 . Assim, observa-se que a média da percepção dos servidores quanto ao clima organizacional não foi significativamente superior a $4,00\left(\mathrm{t}_{(131)}\right.$ $=-0,478$; p-valor $=0,633)$, sendo estimada com $95 \%$ de confiança de estar entre 3,74 e 4,15. Esse resultado não possibilita rejeitar $\mathrm{H0}$ e, assim, não se pode admitir que existam evidências afirmando que os entrevistados, de maneira geral, percebem o clima organizacional na autarquia como satisfatório.

Tabela 3 - Teste T para avaliação do Clima Organizacional

\begin{tabular}{|c|c|c|c|c|c|c|}
\hline & \multirow{2}{*}{ Distribuição $t$} & \multirow{2}{*}{$\begin{array}{l}\text { Valor da } \\
\text { Significância }\end{array}$} & \multirow{2}{*}{$\begin{array}{l}\text { Diferença } \\
\text { da média }\end{array}$} & \multicolumn{2}{|c|}{ Limites do intervalo de confiança } & \multirow{2}{*}{$\mathrm{HO}$} \\
\hline & & & & Inferior & Superior & \\
\hline Médias & $-0,478$ & 0,633 & $-0,0492$ & $-0,253$ & 0,1546 & Aceita \\
\hline \multicolumn{2}{|c|}{131 graus de liberdade } & \multicolumn{3}{|c|}{ Valor de referência $=4,00$} & \multicolumn{2}{|c|}{ Intervalo de confiança $=95 \%$} \\
\hline
\end{tabular}

Fonte: dados da pesquisa.

\section{CONSIDERAÇÕES FINAIS}

Os resultados da pesquisa e o teste de hipóteses indicaram que, de modo geral, o clima organizacional no local da pesquisa foi consi- derado insatisfatório pelos entrevistados sob as diversas perspectivas; em especial, quanto a aspectos relacionados à remuneração, à modernidade institucional e à valorização dos 
servidores. No entanto, a cooperação entre os servidores apresentou a melhor avaliação do estudo, indicando que esta dimensão representa um ponto forte do clima organizacional.

Como pontos favoráveis, a pesquisa mostrou boa comunicação, tanto com as chefias, quanto com os colegas de trabalho, e a satisfação dos servidores com as tarefas desempenhadas em seu dia a dia. Entretanto, há necessidade de se desenvolver estratégias que contribuam para o aprimoramento da imagem organizacional e a valorização do servidor, assim como criar métodos de progredir as formas de remuneração e adquirir novos equipamentos para o uso diário dos servidores em suas respectivas tarefas, sendo essas as variáveis que mais manifestaram insatisfação.

É importante considerar que o acompanhamento do clima organizacional contribui para delinear estratégias e aperfeiçoar o ambiente organizacional, possibilitando um local de trabalho mais agradável que propicie ações conjuntas. $\mathrm{O}$ resultado da pesquisa recomenda que a administração municipal precisa avançar na valorização dos servidores, no desenvolvimento de planos de carreira e no fortalecimento da meritocracia para, assim, formar equipes de trabalho mais motivadas e produtivas. Os resultados reforçam o entendimento de que as pesquisas de clima podem contribuir com elementos valiosos para a gestão de pessoas na administração pública.

Não obstante a amostragem utilizada na pesquisa ser representativa, destaca-se que os resultados são restritos à autarquia pesquisada. Uma limitação do estudo pode ser atribuída à utilização de questionários como instrumento de coleta de dados. Pois, apesar de as pesquisas com questionários revelarem grande abrangência e praticidade de aplicação, elas não permitem captar percepções e sentimentos, que são naturalmente aspectos de caráter subjetivos, não alcançados pelos questionários. Para superar essa limitação, uma pesquisa complementar com abordagem qualitativa poderia contribuir, tanto para a interpretação dos resultados mostrados neste estudo, quanto para a seleção das estratégias mais adequadas de intervenção.

\section{ORGANIZATIONAL ENVIRONMENT AND MUNICIPAL PUBLIC ADMINISTRATION: AN INVESTIGATION IN BELÉM DO PARÁ, BRAZIL}

\section{ABSTRACT}

Studies show that researches on organizational environment have advanced in public administration. However, researches in such organizations are still far from producing similar results to those achieved in the private sector. To contribute to said investigations, this study aimed at analyzing the organizational environment in a Municipal Autarchy of the city of Belém do Pará, in Brazil. The exploratory and descriptive research was performed in the field, with simple random probabilistic sampling made up of one hundred thirty-two employees. Data processing was quantitative, using inferential and descriptive statistics (T Test). Results showed that cooperation and job satisfaction were the dimensions that contributed the most to the quality of workplace environment. However, the overall evaluation did not enable to state that the employees perceive a favorable organizational environment in the Autarchy, a result that was confirmed through the testing of the hypothesis.

Keywords: Organizational behavior. Personnel management. Organizational environment.

\section{AMBIENTE ORGANIZACIONAL Y ADMINISTRACIÓN PÚBLICA MUNICIPAL: UNA INVESTIGACIÓN EN LA CIUDAD DE BELÉM DO PARÁ, BRASIL}

\section{RESUMEN}

Estudios demuestran que investigaciones de ambiente organizacional han avanzado en la administración pública. Con todo, las investigaciones en esas organizaciones todavía están 
lejos de producir resultados semejantes a los alcanzados en la iniciativa privada. Para contribuir con esas investigaciones, ese estudio tuvo como objetivo analizar el ambiente organizacional en una autarquía del municipio de Belém do Pará. La investigación, de carácter exploratorio y descriptivo, fue realizada en trabajo de campo, con muestreo probabilístico aleatorio sencillo, con la participación de 132 funcionarios. El tratamiento de los datos fue cuantitativo y utilizó estadística descriptiva e inferencial (Teste T). Los resultados revelaron que la cooperación y la satisfacción con el trabajo fueron las dimensiones que más contribuyeron para la calidad del ambiente laboral. Sin embargo, la evaluación general no posibilitó afirmar que los funcionarios perciban un ambiente organizacional favorable en la autarquía, resultado confirmado por el teste de hipótesis.

Palabras-clave: Comportamiento organizacional. Gestión de personas. Ambiente organizacional.

\section{L'ENVIRONNEMENT ORGANISATIONNEL ET L'ADMINISTRATION PUBLIQUE MUNICIPALE: UNE INVESTIGATION DANS LA VILLE DE BELEM DO PARA, AU BRESIL}

\section{RESUME}

Des études démontrent que les recherches sur l'environnement organisationnel ont avancé dans l'administration publique. Cependant, les recherches dans ces organisations sont encore loin de produire des resultats similaires à ceux accomplis dans le secteur privé. Pour contribuer avec cettes investigations, cette étude avait comme objectif analiser l'environnement organisationnel dans une autarcie de la ville de Belém do Pará. La recherche, de caractère exploratoire et descriptif, a eu lieu à travers une étude sur le terrain, avec un échantillonnage probabilistique aléatoire simple, avec la participation de 132 fonctionnaires. Le traitement des données a été quantitatif et a utilisé la statistique descriptive et déductive (Test $\mathrm{T}$ ). Les résultats ont révélé que la coopération et la satisfaction avec le travail ont été les dimensions qui ont le plus contribué pour la qualité de l'environement laboral. Néanmoins, l'évaluation générale n'a pas permis d'afirmer que les fonctionnaires perçoivent un climat organisationnel favorable dans l'autarcie, un résultat qui a été confirmé par le test de l'hypothèse.

Mots-clés: Comportement organisationnel. Gestion de personnel. Environement organisationnel.

\section{REFERÊNCIAS}

ABREU, N. R. et al. Comunicação e os fatores externos intervenientes no clima organizacional em um hospital universitário. Qualitas Revista Eletrônica, Campina Grande, v. 14, n. 1, p. 1-15, jan./jun. 2013. Disponível em: <http:// revista.uepb.edu.br/index.php/qualitas/article/ view/1585>. Acesso em: 26 jul. 2016.

ARABACI, B. Academic and administration personnel's perceptions of organizational climate (Sample of Education Faculty of Firat University). Procedia, United Kingdom, v. 2, n. 2, p. 4445-4450, 2010. Disponível em: $<$ http:// ac.els-cdn.com/S1877042810007494/1-s2.0-S1877042810007494-main.pdf?_tid=dbb58cfc-5340-11e6-aefc-00000aab0f02\&acdnat $=1469$ 545051 a71 ee8e1562a68beed6b8c70202f2ffa>. Acesso em: 23 jul. 2016.

ARAÚJO, L. C. G.; GARCIA, A. A. Gestão de pessoas. São Paulo: Atlas, 2009.

BERGUE, S. B. Gestão estratégica de pessoas no setor público. São Paulo: Atlas, 2014.

BRUNI, A. L. SPSS aplicado à pesquisa acadêmica. São Paulo: Atlas, 2009.

CARAPETO, C.; FONSECA, F. Administração pública. Lisboa: Sílabo, 2014. 
CODA, R. Pesquisa de clima organizacional e gestão estratégica de recursos humanos. In: BERGAMINI, C. W.; CODA, R. Psicodinâmica da vida organizacional: motivação e liderança. São Paulo: Atlas, 1997.

COLOSSI, N. Clima organizacional. Florianópolis: CPGA; UFSC, 1991.

COMBS, J. et al. How much do high-performance work practices matter? A meta-analysis of their effects on organizational performance. Personnel Psychology, United States, n. 3, v. 59, p. 501-528, 2006. Disponível em: $<$ http://onlinelibrary.wiley.com/doi/10.1111/j. 1744-6570.2006.00045.x/full>. Acesso em: 16 jun. 2016.

COSTA, F. J. Mensuração e desenvolvimento de escalas. Rio de Janeiro: Editora Ciência Moderna, 2011.

D'ALLEO, G.; SANTANGELO, A. Organizational Climate and Burnout in Call-Center Operators. Procedia, n. 30, p. 1608-1615, 2011. Disponível em: <http://www.sciencedirect. com/science/article/pii/S1877042811021379>. Acesso em: 24 jun. 2016.

FARIAS, P. C. L.; GAETANI, F. A política de recursos humanos e a profissionalização da administração pública no Brasil do século XXI: um balanço provisório. In: CONGRESSO INTERNACIONAL DEL CLAD SOBRE LA REFORMA DEL ESTADO Y DE LA ADMINISTRACIÓN PÚBLICA, 7., 2002, Lisboa. Anais... Lisboa, 2002. Disponível em: $<$ http:// www.bresserpereira.org.br/documents/mare/ rh/05gaetanirh.pdf $>$. Acesso em: 16 jun. 2016.

FERREIRA, M. R. L. et al. Gestão de pessoas no setor público: análise do processo de socialização de novos concursados. In: SEMINÁRIO EM ADMINISTRAÇÃO, 10., 2007, São Paulo. Anais... São Paulo: FEA/USP, 2007.

FOREHAND, G. A; GILMER, B. H. Environ- mental variation in studies of organizational behavior. Psychological Bulletin, United States, v. 62, n. 6, p. 361-382, 1964.

GONÇALVES, C. A. M. Cultura e clima organizacional: contributos da motivação e das competências de gestão de líderes. Mangualde: Pedagogo, 2012.

HAIR JUNIOR, J. F. et al. Análise multivariada de dados. São Paulo: Bookman, 2009.

HEINZMANN, L. M.; SILVA, M. G. Análise do clima organizacional da junta comercial do estado de Mato Grosso. Revista da Faculdade de Administração e Economia, São Paulo, v. 6, n. 1, p. 146-169, jan./jul. 2014. Disponível em: <https://www.metodista.br/revistas/revistas-ims/index.php/ReFAE/article/view/4394>. Acesso em: 20 jun. 2016.

HOLLOWAY, J. B. Leadership Behavior and organizational climate: na empirical study in a non-profit organizational. Energing Leandership Journeys, Virginia Beach, v. 5, n. 1, p. 9 -35, 2012. Disponível em: <http://www.regent. edu/acad/global/publications/elj/vol5iss1-/ ELJ_Vo15No1_Holloway_pp9-35.pdf > . Acesso em: 2 jun. 2016.

HUNTER, E. M.; PERRY, S. J.; CURRAL, S. C. Inside multi-disciplinary science and engineering research centers: the impact of organizational climate on invention disclosures and patents. Research Policy, Netherlands, v. 40, p. 4226-1239, 2011. Disponível em: <http:// www.sciencedirect.com/science/article/pii/ S0048733311001053>. Acesso em: 7 jul. 2016.

KETTL, D. F. A revolução global: reforma da administração do setor público. In: BRESSER-PEREIRA, L. C.; SPINK, P. K. (Org.). Reforma do Estado e administração pública gerencial. Rio de Janeiro: FGV, 2005.

KLINE, R. B. Principles and practice of structural equation modeling. New York: 
The Guilford Press, 1998.

KOLB, D. A; RUBIN, I.; MCLNTYRE, J. Organizational psychology: an experimental approach. New Jersey: Prentice Hall, 1978.

KUBO, E. K. M. et al. Frankenstein e o clima organizacional: estudo bibliográfico sobre um construto indefinido. Revista Internacional de Investigación em Ciencias Sociales, Asunción-Paraguay, v. 11, n. 1, p. 35-54, jan./jul. 2015. Disponível em: $<$ http://revistacientifica.uaa.edu.py/index.php/riics/article/ view/251/223>. Acesso em: 25 jun. 2016.

LA FOLLETE, W. R.; SIMS, H. P. Is satisfaction redundant with organizational climate? Organizational Behavior and Human Performance, v. 13, n. 2, p. 257-278, 1975.

LIM, S.; EO, S. The mediating roles of collective teacher efficacy in the relations of teaches' perceptions of school organizational climate to their burnout. Teaching and Teacher Education, v. 44, p.1 38-147, nov. 2014. Disponível em: $\quad<$ http://www.sciencedirect.com/science/ article/pii/S0742051X14001048>. Acesso em: 25 jun. 2016.

LITWIN, G. H; STRINGER, R. A. Motivation and organizational climate. Cambridge: Harvard University Press, 1968.

LUZ, R. Gestão do clima organizacional. Rio de Janeiro: Qualitymark, 2012.

MALHOTRA, N. K. Pesquisa de marketing: uma orientação aplicada. São Paulo: Bookman, 2011.

MANTOVANI, A. P.; GREATTI, L. Avaliação do clima organizacional e comprometimento das equipes. Maringá Management - Revista de Ciências Empresariais, Maringá, v. 7, n. 1, p. 7-15, jan./jun. 2010. Disponível em: <www.maringamanagement.com.br/novo/index.php/ojs/article/ download/112/pdf $>$. Acesso em: 18 jun. 2016.
MARTINS, M. C. F. Clima organizacional: medidas do comportamento organizacional: ferramentas de diagnóstico e de gestão. Porto Alegre: Artmed, 2008.

MATOS, J. G. Análise do ambiente corporativo: do caos organizado o planejamento estratégico das organizações. Rio de Janeiro: E-Papers, 2007.

MATtOS, C. A. C. et al. Contexto de trabalho: uma investigação entre os professores e técnicos administrativos de uma instituição federal de ensino superior. Revista de Estudos Sociais, Cuiabá, v. 17, n. 33, p. 72-91, jun./ dez. 2015. Disponível em: <http://periodicoscientificos.ufmt.br/ojs/index.php/res/article/ view/2299/pdf>. Acesso em: 25 jun. 2016.

MELlO, M. L. B. C.; AMÂNCIO FILHO, A. A. A gestão de recursos humanos em uma instituição pública brasileira de ciência e tecnologia em saúde: o caso Fiocruz. Revista de Administração Pública, Rio de Janeiro, v. 44, n. 3. p. 613-636, maio/jun. 2010. Disponível em: $<$ http://www.scielo.br/pdf/rap/v44n3/04.pdf $>$. Acesso em: 15 jun. 2016.

MELLO, M. S. O. A qualidade do clima organizacional como variável interveniente no desempenho humano no trabalho: um estudo de caso da empresa HERBARIUM. 2004. 368 f. Dissertação (Mestrado em Engenharia de Produção) - Programa de Pós-Graduação em Engenharia de Produção, Universidade Federal de Santa Catarina, Santa Catarina, 2004.

MÓL, A. L. R. et al. Clima organizacional na administração pública. Rio de Janeiro: FGV, 2010.

MORO, A. B. et al. Avaliação do clima organizacional dos servidores técnicos-administrativos de uma instituição pública de Ensino. In: ENCONTRO DE ADMINISTRAÇÃO PÚBLICA E GOVERNO, 2012, Salvador. Anais... Salvador: ANPAD, 2012. 
MOTTA, K. A. M. B. A mediação do suporte na relação entre o estilo gerencial e o clima organizacional. 2006. 118 f. Dissertação (Mestrado em Psicologia) - Programa de Pós-Graduação em Psicologia, Universidade Católica de Goiás, Goiana, 2006.

PATTERSON, M. G. et al. Validating the organizational climate measure: links to Managerial Practices, Productivity and Innovation. Journal of Organizational Behavior, United States, v. 26, p. 379-408, abr. 2005. Disponível em: <http://onlinelibrary.wiley.com/ doi/10.1002/job.312/abstract>. Acesso em: 26 jul. 2016.

PELZ, D.; ANDREWS, F. Scientists in organizations: productive climates for research and development. New York: Wiley, 1966.

PEREIRA, J. C.; NASSER, A. A gestão do clima na coordenação geral de sangue e hemoderivados como estratégia para o desenvolvimento organizacional. In: CONGRESSO DE GESTÃO PÚBLICA, 6., 2013, Brasília. Anais... Brasília: CONSAD, 2013.

PEREIRA, J. M.; VIDAL, M. A influência do clima organizacional no desempenho das Pessoas: um estudo de caso no Fórum da Comarca de Bezerros. Veredas, Pernambuco, v. 4, n.1 p. 123-138, jan./jun. 2011. Disponível em: $<$ http:// veredas.favip.edu.br/ojs/index.php/veredas 1/ article/view/87>. Acesso em: 25 jun. 2016.

PINHEIRO, R. M. et al. Comportamento do consumidor e pesquisa de mercado. Rio de Janeiro: FGV, 2009.

RIBEIRO, L. M. de P.; PEREIRA, J. R.; BENEDICTO, G. C. As reformas da Administração Pública Brasileira: uma contextualização do seu cenário, dos entraves e das novas perspectivas. In: ENCONTRO DA ASSOCIAÇÃO NACIONAL DE PÓS-GRADUAÇÃO EM ADMINISTRAÇÃO, 37., 2013, Rio de Janeiro. Anais... Rio de Janeiro: ANPAD, 2013.
RIZZATTI, G. Análise de fatores significativos do clima organizacional da UFSC: contribuição para implantação do programa de qualidade. Florianópolis. 1995. 217 f. Dissertação - (Mestrado em Administração) - Universidade Federal de Santa Catarina, Programa de Pós-Graduação em Administração, Florianópolis, 1995.

ROBBINS, S. P. Comportamento organizacional. São Paulo: Prentice Hall, 2014.

SALGADO NETO, J. B. Clima Organizacional da UEMA: uma contribuição ao programa "Uma Universidade para o Maranhão. Florianópolis." 2001. 170 f. Dissertação (Pós-Graduação em Administração) - Departamento de Ciências da Administração, Universidade Federal de Santa Catarina, 2001.

SALGADO, C. C. R.; AIRES, R. F. F.; ARAÚJO, A. G.; Clima organizacional: um estudo de uma superintendência estadual de um banco múltiplo. Tekhne e Logos, São Paulo, v. 4, n. 2, p. 51-64, maio/ago. 2013. Disponível em: $<$ http://www.fatecbt.edu.br/seer/index.php/tl/ article/view/203>. Acesso em: 25 jul. 2016.

SALVADOR, N. G.; MACHADO, R. A. A.; ALMEIDA, L. I. R. Impactos do excesso de burocracia e da falta de padronização de processos no clima organizacional: um estudo de caso na matriz da rede de hortifrutigranjeiros Alpha S/A. Destarte, Vitória, v. 3, n. 2, p. 110127, out. 2013.

SAMPIERI, R. H.; COLLADO, C. F.; LUCIO, P. B. Metodologia de pesquisa. São Paulo: McGraw-Hill, 2013.

SANTOS, N. M. B. F. Clima organizacional: pesquisa e diagnóstico. Lorena: Stiliano, 1999.

SBRAGIA, R. Um estudo empírico sobre clima organizacional em instituições de pesquisa. Rev. Adm., São Paulo, v. 18, n. 2, p. 7-17, abr./jun. 1983.

SCHNEIDER, B. Organizational climate: in- 
dividual preferences and organizational realities. Journal pf Applied Psycology, Washington, n. 56, p. 211-217, 1978.

SHIM, M. Factors influencing child welfare employee's turnover: focusing on organizational culture and climate. Children and Youth Services Review, United Kingdom, n. 32, p. 847 - 856, jun. 2010. Disponível em: $<$ http:// www.sciencedirect.com/science/article/pii/ S0190740910000472>. Acesso em: 1 jul. 2016.

SILVA, F. M.; MELLO, S. P. T. A implantação da gestão por competências: práticas e resistências no setor público. Revista Eletrônica de Administração e Turismo, Pelotas, v. 2, n. 1, p. 110127, jan.jun. 2013.

SILVA, N. T. da. Clima organizacional: uma proposta dos fatores a serem utilizados para avaliação do clima de uma instituição de ensino superior. 2003. 138 f. Dissertação (Mestrado em Engenharia de Produção) - Programa de Pós-Graduação em Engenharia de Produção, Universidade de Santa Catarina, Florianópolis, 2003.

SIQUEIRA, M. M. M. Satisfação no trabalho. In: SIQUEIRA, M. M. M. (Org.). Medidas do comportamento organizacional: ferramentas de diagnóstico e de gestão. Porto Alegre: Artmed, 2008.

SPIRI, W. C. Estudo sobre a percepção do clima organizacional do centro cirúrgico de um hospital especializado. Revista Latino-Americana de Enfermagem, Ribeirão Preto, v. 6, n. 1, p. 11-14, jan. 1998. Disponível em: <http:// www.scielo.br/scielo.php?script=sci_arttext\&pid=S0104-11691998000100003>. Acesso em: 20 jul. 2016.

TAMAYO, A. Cultura e saúde nas organizações. Porto Alegre: Artmed, 2004.

VIEIRA, C. B. C. et al. Motivação na administração pública: considerações teóricas sobre a aplicabilidade dos pressupostos das teorias mo- tivacionais na esfera pública. Revista ADMpg Gestão Estratégica, Paraná, v. 4, n. 1, jan./ jun. 2011. Disponível em: <http://www.admpg. com.br/revis-ta2011/artigos/12.pdf $>$. Acesso em: 25 jul. 2016. 